\title{
Beta-Adrenergic Receptors Gene Polymorphisms are Associated With Cardiac Contractility and Blood Pressure Variability
}

\section{Lenka MATUSKOVA ${ }^{1}$, Barbora CZIPPELOVA ${ }^{2}$, Zuzana TURIANIKOVA ${ }^{2}$, David SVEC ${ }^{\mathbf{1}}$, Zuzana KOLKOVA ${ }^{2}$, Zora LASABOVA ${ }^{3}$, Michal JAVORKA ${ }^{1}$}

${ }^{1}$ Department of Physiology, Comenius University in Bratislava, Jessenius Faculty of Medicine in Martin, Martin, Slovak Republic, ${ }^{2}$ Biomedical Center Martin, Comenius University in Bratislava, Jessenius Faculty of Medicine in Martin, Martin, Slovak, Republic, ${ }^{3}$ Department of Molecular Biology and Genomics, Comenius University in Bratislava, Jessenius Faculty of Medicine in Martin, Martin, Slovak Republic

Received April 19, 2021

Accepted November 11, 2021

\section{Summary}

$\beta$-adrenergic receptors ( $\beta$-ARs) play a pivotal role in the cardiovascular regulation. In the human heart $\beta_{1}$ - and $\beta_{2}$-ARs dominate in atria as well as in ventricle influencing heart rate and myocardial contractility. Some single nucleotide polymorphisms (SNPs) of $\beta$-ARs might influence cardiovascular function. However, the influence of $\beta$-AR genes SNPs on hemodynamic parameters at rest and their reactivity under stress is still not well known. We aimed to explore the associations between four selected $\beta$-ARs gene polymorphisms and selected cardiovascular measures in eighty-seven young healthy subjects. While in $\beta_{1}-A R$ polymorphism rs1801252 no significant association was observed, second $\beta_{1}$-AR polymorphism rs1801253 was associated with decreased cardiac output and cardiac index during all phases and with decreased flow time corrected and ejection time index at rest and during mental arithmetics. Polymorphism rs1042713 in $\beta_{2}$-AR was associated with alterations in blood pressure variability at rest and during head-up-tilt, while rs1042714 was associated predominantly with decreased parameters of cardiac contractility at rest and during mental arithmetics. We conclude that complex analysis of various cardiovascular characteristics related to the strength of cardiac contraction and blood pressure variability can reveal subtle differences in cardiovascular sympathetic nervous control associated with $\beta$-ARs polymorphisms.

\section{Key words}

Beta-adrenergic receptors • Polymorphism • Contractility • Blood pressure variability

\section{Corresponding author}

L. Matuskova, Department of Physiology, Comenius University in Bratislava, Jessenius Faculty of Medicine in Martin, Malá Hora 4C, 03601 Martin, Slovakia. E-mail: sopkova22@uniba.sk

\section{Introduction}

$\beta$-Adrenergic receptors $(\beta$-adrenoceptors, $\beta$-ARs) play a pivotal role in the cardiovascular control. Three different $\beta$-adrenoceptor subtypes have been identified pharmacologically: $\beta_{1^{-}}, \quad \beta_{2^{-}}$and $\beta_{3}$-adrenoceptors (Bylund et al. 1994). In the human heart, both $\beta_{1}$ and $\beta_{2}$-AR coexist, with $\beta_{1}$-AR subtype predominates in atrial as well as in ventricular tissue (Brodde and Michel 1999), influencing heart rate and contractility. $\beta$-ARs are polymorphic and several single nucleotide polymorphisms (SNPs) might influence the receptors function potentially resulting in altered cardiovascular control and development of cardiovascular disease (Leineweber and Brodde 2004, Ahles and Engelhardt 2014).

Previous in vitro studies revealed that two common polymorphisms in $\beta_{1}$-AR - rs 1801252 (Ser49Gly), rs1801253 (Arg389Gly) - and two in the $\beta_{2}$-AR - rs1042713 (Arg16Gly), rs1042714 (Gln27Glu) appear to influence receptor function (e.g. Ahles et al. 2011, Chong et al. 2000, Levin et al. 2002, Zhang and Steinberg 2013). Clinical studies found associations of these $\beta$-AR polymorphisms with hypertension (e.g. Ge et al. 2005, Johnson et al. 2011) increased incidence 
of cardiovascular events ( $\mathrm{Li}$ et al. 2019), obesity (Aradillas-García et al. 2017) and insulin resistance (Mitra et al. 2019). Moreover, pharmacogenomic studies observed altered responses to $\beta$-agonists and antagonists associated with $\beta$-AR polymorphisms (e.g. Johnson et al. 2003, Bruck et al. 2005). Despite the fact, that some of the adrenoceptor variants range among the most frequently studied polymorphisms assessed to date, their functional impact still remains unclear. To demonstrate their effect on cardiovascular control as a possible link between various SNPs and an increased risk of pathological states, several studies were conducted on healthy subjects focused on the association between selected SNPs and indices reflecting cardiac chronotropic and inotropic control. Up to the present, polymorphisms of $\beta$-AR have been associated with altered heart rate (e.g. Eisenach et al. 2012, Atala et al. 2015), blood pressure (Masuo et al. 2005, Tikhonoff et al. 2008), heart rate variability (Matsunaga et al. 2007a, Yang et al. 2011, Atala et al. 2015), cardiac contractility measures (e.g. La Rosée et al. 2004, Kindermann et al. 2011) and selected hemodynamic parameters, including cardiac output, stroke volume and ejection fraction (e.g. Tang et al. 2003, Wittwer et al. 2011).

Above mentioned studies suffer from several limitations, including smaller study size, limited number of assessed measures not encompassing the complexity of sympathetic cardiac control, the relatively wider age range, and evaluation of parameters mostly at rest or during one selected stressor application. To date, there is no study performed on a sufficiently large group of young healthy subjects with a simultaneous continuous measurement of variety of cardiovascular and hemodynamic parameters reflecting cardiac chronotropy and inotropy not only at rest, but also their reactivity during the application of standardized stressors.

Therefore, the aim of our study was to find potential association of four selected $\beta$-AR polymorphisms with a set of cardiovascular measures in a group of healthy young subjects in the relatively narrow age range. In addition to resting state, protocol included two challenges separated by a recovery phase orthostatic stress and cognitive load enabling to reveal potential effect of SNPs on cardiovascular reactivity.

\section{Methods}

\section{Subjects}

Eighty-seven healthy adolescents and young adults (53 female, 34 male) with age ranging from 16 to
24 years were recruited for our study. All subjects were instructed not to use substances influencing autonomic nervous system or cardiovascular activity before the examination. We excluded subjects with any current or previous infectious disease (at least three weeks prior to the examination date), cardiovascular disease including hypertension (diagnosed using 24-h ambulatory blood pressure monitoring following examination), diabetes mellitus, psychiatric disorders, and hypothyroidism. All female subjects were examined in the proliferative phase $\left(6^{\text {th }}-13^{\text {th }}\right.$ day $)$ of their menstrual cycle. All participants or parental guardian (in subjects below 18 years of age) gave their written informed consent prior to examination.

The study was approved by the Ethics Committee of Jessenius Faculty of Medicine, Comenius University in accordance with the Declaration of Helsinky (2000) of the World Medical Association. During recordings, the volunteers were asked to avoid disturbing movements and speaking.

\section{Genetic analysis}

DNA was isolated from whole blood by a QIAamp DNA Blood Midi Kit (Qiagen, Hilden, Germany). Two polymorphisms of $\beta_{1}$-AR in gene $A D R B 1$ (rs1801252, rs1801253) and two of $\beta_{2}$-AR in gene $A D R B 2$ (rs1042713, rs1042714), located in exons were genotyped. They cause missense mutation - a sequence variant, that changes one base, resulting in a different amino acid sequence with the preserved length. All of them were functionally studied, with different conclusions, but majority of studies indicated altered receptor function and regulation. Genotypes were detected by real-time polymerase chain reaction (RT-PCR) by TaqMan single nucleotide polymorphism Genotyping Assays.

\section{Study protocol}

Participants were examined under standardized conditions in a quiet room from 8 to $12 \mathrm{AM}$. All of them were instructed to lie comfortably in the supine position and not to speak or move unnecessarily. The whole protocol was divided into five phases as follows (for more details see: Javorka et al. 2018, Krohova et al. 2018).

Phase 1 (Rest): the subjects were lying in supine position at rest for $15 \mathrm{~min}$.

Phase 2 (Head up tilt - HUT): the subjects were tilted up to 45 degrees on the motor driven table for $8 \mathrm{~min}$ to evoke mild orthostatic stress. The lower degree of tilt compared to more often used 60 degrees was chosen to 
increase tolerability of subjects to study protocol while still shifting autonomic nervous system activity towards an increased sympathetic and decreased parasympathetic activity.

Phase 3 (Rest): the subjects were lying in supine position to recover for $10 \mathrm{~min}$.

Phase 4 (mental arithmetics - MA): the subjects performed cognitive challenge - a non-verbal mathematical task displayed on the ceiling of the examination room by data projector in the supine position for $6 \mathrm{~min}$. During MA, the subject was disturbed by the rhythmic sound of a metronome and instructed to perform the task as quickly as possible with a minimal error rate.

Phase 5 (Rest): the subjects were lying supine to recover for $10 \mathrm{~min}$.

\section{Data acquisition}

We measured cardiovascular parameters during whole study protocol. Continuous finger arterial blood pressure (BP) was measured by photoplethysmographic volume-clamp method (FinometerPro, FMS, Netherlands) and ECG signal was recorded from bipolar thoracic lead (Cardiofax ECG-9620, NihonKohden, Japan). Both signals were digitized at a sampling rate of $1000 \mathrm{~Hz}$. After detection of R waves from the ECG signal and systolic and diastolic BP (SBP and DBP) values from the reconstructed brachial BP signal, beat-to-beat time series consisting of SBP, DBP values and RR intervals were generated. Impedance cardiography (CardioScreen 2000, Medis, Germany) was used for a beat to beat recording of hemodynamic parameters stroke volume (SV), stroke index (SI), cardiac output (CO), cardiac index (CI) and indices related to left ventricular contractility, including selected systolic time intervals: velocity index (VI), acceleration index (ACI), preejection period (PEP), left ventricular ejection time (LVET), ejection time index (ETI) and flow time corrected (FTc).

\section{Data analysis}

We analyzed 300 heart beats long segments selected from each phase. For the $1^{\text {st }}$ phase the analyzed segment started $8 \mathrm{~min}$ after the beginning of the measurement, for $2^{\text {nd }}$ phase it started 3 min after the change of position from supine to tilt, for the $3^{\text {rd }}$ phase we analyzed segment starting $3 \mathrm{~min}$ after the subject was tilted back to supine position, for the $4^{\text {th }}$ phase it started 2 min after the beginning of the cognitive task. In the last phase, the analyzed segment started $3 \mathrm{~min}$ after its beginning. From all beat to beat measures we calculated mean values. RR, SBP and DBP oscillations underwent linear time and frequency domain analysis of heart rate (HRV) and systolic or diastolic blood pressure variability (BPV), respectively. Measures describing the magnitude of HRV or BPV are partially influenced by sympathetic cardiovascular control.

\section{Heart rate variability (HRV) analysis}

In the time domain, we calculated two most commonly used measures: standard deviation of normal RR intervals (SD RR), reflecting the overall variability magnitude; and the root mean square of successive beatto-beat differences (RMSSD RR), reflecting the magnitude of instantaneous RR intervals changes. In the frequency domain, spectral analysis was performed using fast Fourier transform to obtain spectral powers in low-frequency (LF HRV: $0.04-0.15 \mathrm{~Hz}$ ) and high-frequency (HF HRV: 0.15-0.5 Hz) bands.

\section{Blood pressure variability (BPV) analysis}

From SBP and DBP oscillations, we have also calculated standard deviation of systolic blood pressure values (SD SBP), standard deviation of diastolic blood pressure values (SD DBP) - measures reflecting overall magnitude of BP oscillations and root-mean-square of successive differences of SBP or DBP values (RMSSD SBP, RMSSD DBP) - respectively quantifying beat-tobeat variability.

Using spectral analysis, we obtained spectral powers in low-frequency (LF) and high-frequency (HF) bands for both systolic and diastolic BPV. As a result, four indices were calculated for each analyzed segment: LF SBP, HF SBP, LF DBP and HF DBP.

\section{Statistics}

For statistical analysis we used the software SYSTAT 13 (Systat Software Inc., USA). Due to the non-Gaussian distribution of assessed variables, the Mann-Whitney U-test was used for between-groups comparison. Two groups were defined based on the presence of one selected allele within given SNP. Statistical significance was considered at values $p<0.05$.

Correction for multiple testing was completed using the Benjamini-Hochberg correction to decrease the false discovery rate (FDR) (Benjamini and Hochberg 1995). Since previous studies (Bondar et al. 2017, Lu et al. 2018, Maisano Delser et al. 2018) pointed that the original methodology is too conservative for genomics applications and results in a substantial loss of 
statistical power, we used a more relaxed criteria $(\mathrm{FDR}=0.1)$ in our study.

\section{Results}

We genotyped four polymorphisms of $\beta$-ARs in our population of 87 healthy Slovak Caucasian subjects with basic characteristics presented in Table 1. Genotypes and allele frequencies for each polymorphism determined in the study are shown in Table 2. In the entire study sample, allele and genotype frequencies were concordant with the Hardy-Weinberg equilibrium $(p>0.05)$ and genotypes frequency distributions and allele frequencies of SNPs were similar to previously published data. There were no significant differences in sex, age, height, body weight or body mass index between genotypes. For each comparison of assessed cardiovascular measures, we selected two groups based on the presence one of allele within given polymorphism. e.g. for rs1042714 polymorphism, we compared subjects with presence of allele $\mathrm{C}$ (aggregated groups $\mathrm{CC}$ with $\mathrm{CG}$ ) with subjects without allele $\mathrm{C}$ (homozygotes $\mathrm{GG}$ ); alternatively, we also tested for this polymorphism effect of the presence of allele $\mathrm{G}$ (aggregated groups $\mathrm{GG}$ and $\mathrm{CG}$ ) with subjects without allele $\mathrm{G}$ (homozygotes $\mathrm{CC}$ ). From intended 8 tests for each cardiovascular measure (two for each SNP) we did not perform two tests due to a small frequency of minor allele occurrence (testing of the effect of allele A presence for rs1801252 (with only 1 subject in GG group) and testing of the effect of allele $C$ for rs1801253 (with only 4 subjects in GG group)). In total, 6 tests were performed for each cardiovascular measure to test the effect of four selected $\beta$-ARs SNPs.

Table 1. The main characteristics of subjects. Values are presented as median (interquartile range).

\begin{tabular}{lc}
\hline & Study subjects \\
\hline Age (years) & $18.5(17.5-20.7)$ \\
Height $(\mathrm{cm})$ & $172.3(164.9-180.1)$ \\
Body weight $(\mathrm{kg})$ & $61.6(55.4-71.5)$ \\
Body mass index $\left(\mathrm{kg} / \mathrm{m}^{2}\right)$ & $21.2(19.8-23.0)$ \\
Fat mass $(\%)$ & $20.2(15.9-24.7)$ \\
Waist-to-hip ratio & $0.76(0.72-0.80)$ \\
Baseline heart rate $($ bpm) & $65.2(60.8-70.6)$ \\
Baseline systolic blood pressure $(\mathrm{mm} \mathrm{Hg})$ & $117.5(111.3-123.3)$ \\
Baseline diastolic blood pressure $(\mathrm{mm} \mathrm{Hg})$ & $80.0(73.8-82.5)$ \\
\hline
\end{tabular}

Table 2. Genotypes and allele frequencies of the studied polymorphisms.

\begin{tabular}{|c|c|c|c|c|c|}
\hline \multirow{2}{*}{$\begin{array}{l}\text { Polymorphism } \\
\text { rs } 1801252\end{array}$} & \multicolumn{3}{|c|}{ Genotypes } & \multicolumn{2}{|c|}{ Allele frequencies } \\
\hline & AA (64) & AG (21) & GG (1) & $\mathrm{A}-87 \%$ & $G-13 \%$ \\
\hline rs 1801253 & CC (49) & CG (33) & GG (4) & $\mathrm{C}-76 \%$ & $\mathrm{G}-24 \%$ \\
\hline$r s 1042713$ & GG (39) & AG (39) & $\mathrm{AA}(10)$ & $G-66 \%$ & $\mathrm{~A}-34 \%$ \\
\hline rs 1042714 & $\mathrm{CC}(22)$ & CG (49) & GG (16) & $\mathrm{C}-53 \%$ & $\mathrm{G}-47 \%$ \\
\hline
\end{tabular}

Associations of cardiovascular measures with $\beta_{1}-A R$ SNPs - effects of rs 1801252 and rs 18012153

No significant effect of rs1801252 polymorphism on assessed measures was found.

In polymorphism rs1801253, although no significant associations were observed for $\mathrm{HR}$ and $\mathrm{BP}$ derived measures, we found significant associations with several hemodynamic parameters derived from impedance cardiography. Carriers of allele G (GG or GC) had decreased $\mathrm{CO}$ and $\mathrm{CI}$ during all phases of study protocol and decreased FTc and ETI at rest and during MA compared with non-carriers of allele $G$ (i.e. in homozygotes CC). After Benjamini-Hochberg correction, the significant differences in $\mathrm{CO}$ during phase 3 and in $\mathrm{CO}$ and $\mathrm{CI}$ in phase 5 were considered as nonsignificant (Fig. 1). 

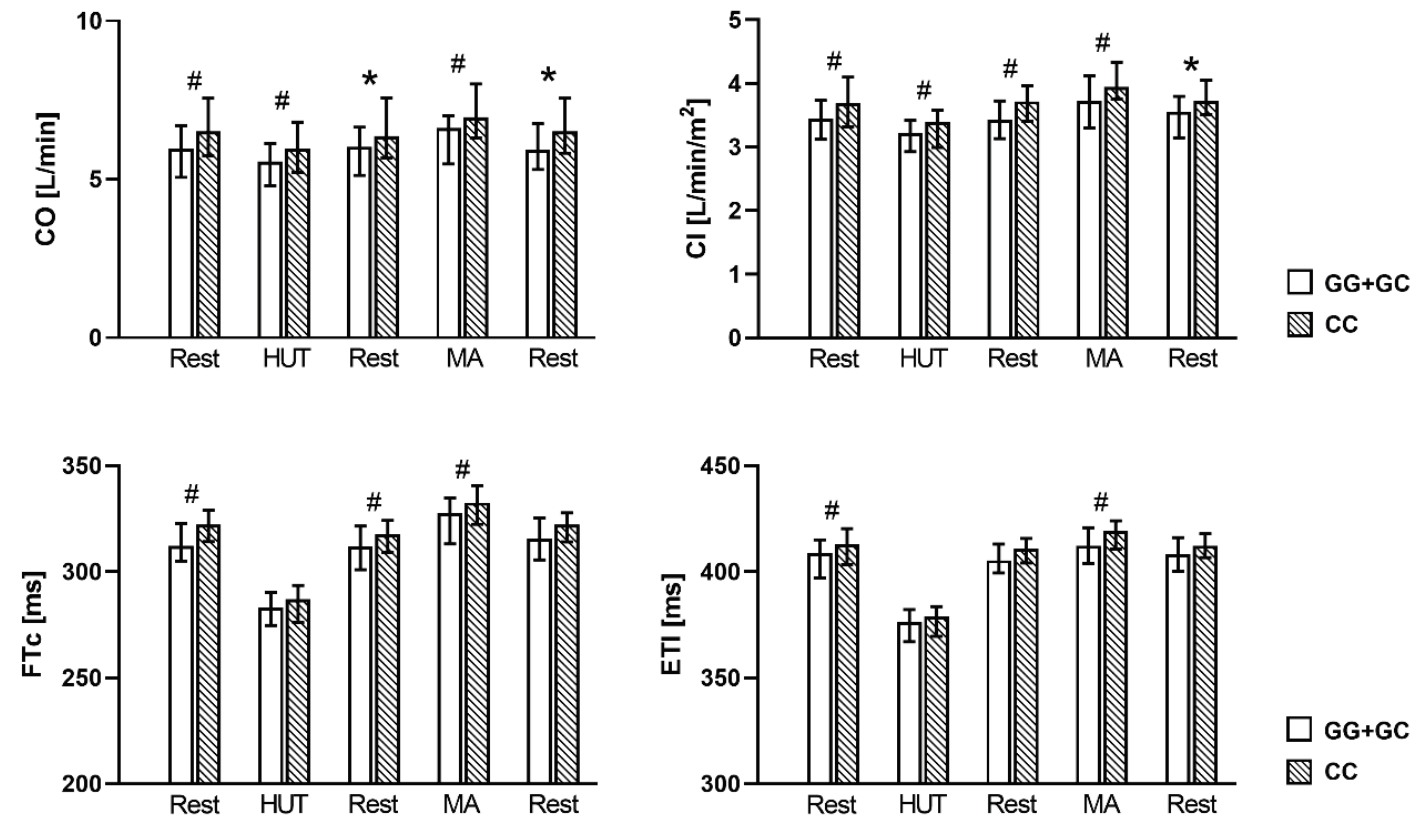

Fig. 1. Cardiac output (CO), cardiac index (CI), ejection time index (ETI) and flow time corrected (FTc) during all phases of study protocol in relation to presence of allele $G$ in polymorphism rs1801253. Bar corresponds to median value, error bars illustrate interquartile range. $*$ denotes statistically significant difference with $\mathrm{p}<0.05 ;{ }^{*}$ denotes statistically significant difference after BenjaminiHochberg adjustment.

Associations of cardiovascular measures with $\beta_{2}$-AR SNPs - effects of rs 1042713 and rs 1042714

In polymorphism rs1042713, we found significant associations with BPV indices (Fig. 2). In more details, carriers of allele $\mathrm{G}$ (GG or GA) had increased BPV magnitude in LF band (LF SBP and LF DBP) and overall
BPV quantified by SD SBP and SD DBP indices during rest and HUT phases of examination protocol. In addition, an increased HF DBP at rest was found in this group. All significant results survived correction for multiple testing. No significant difference between A allele carriers compared to non-carriers in this SNP was found.
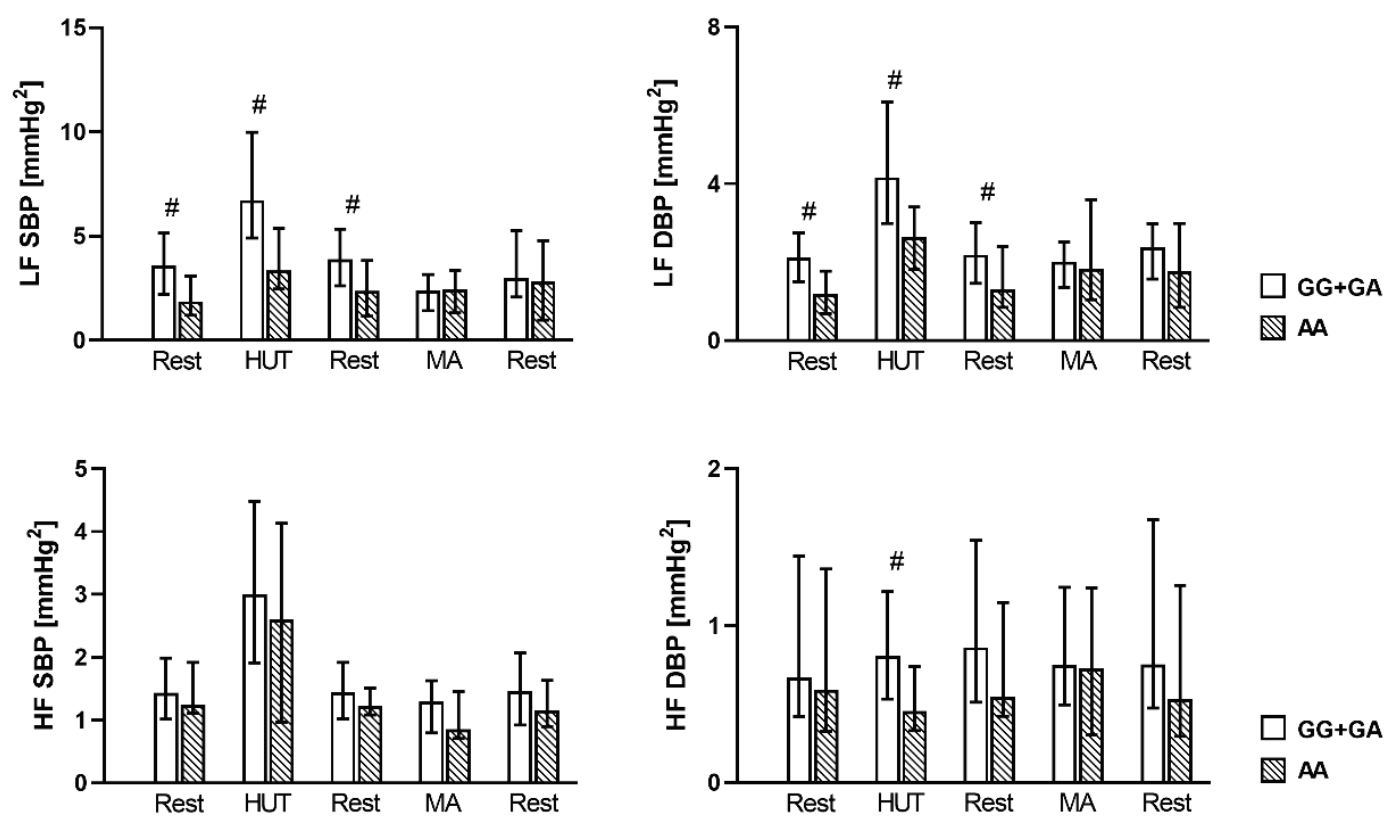

Fig. 2. Blood pressure variability indices - comparison between $G$ allele carriers and noncarriers in polymorphism rs1042713. LF SBP and LF DBP - spectral powers in low frequency band of systolic or diastolic blood pressure variability, respectively. HF SBP and HF DBP - spectral powers in high frequency band of systolic or diastolic blood pressure variability, respectively. Bar corresponds to median value, error bars illustrate interquartile range. * denotes statistically significant difference with $p<0.05 ;$ * denotes statistically significant difference after Benjamini-Hochberg adjustment. 
In polymorphism rs1042714, we found decreased SI and decreased contractility measures (VI, $\mathrm{ACI}$ ) and increased PEP in carriers of allele $\mathrm{C}$ (CC or $\mathrm{CG}$ ) compared to GG homozygotes at rest and during MA phase. Although association with variable PEP in phase 1 did not survive correction for multiple testing, the rest of them survived the Benjamini-Hochberg correction (Fig. 3). No significant difference between G allele carriers compared to non-carriers in this SNP was found. Furthermore, no significant association between $\beta_{2}$-AR SNPs and HR or HRV indices were found.
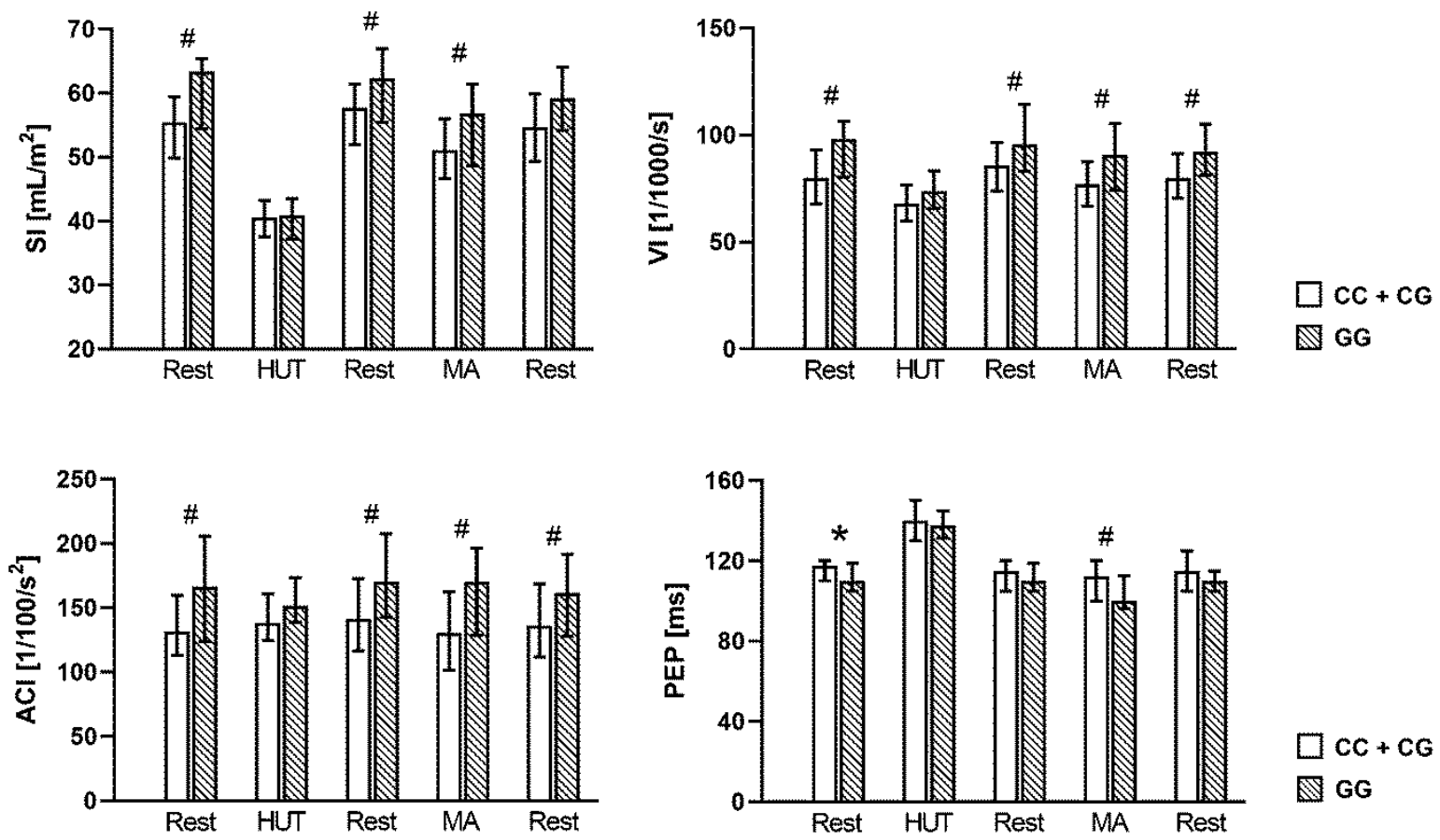

Fig. 3. Stroke index (SI), cardiac contractility related indices velocity index (VI), acceleration index (ACI) and preejection period (PEP) during all phases of study protocol in relation to presence of allele $C$ in polymorphism rs1042714. Bar corresponds to median value, error bars illustrate interquartile range. * denotes statistically significant difference with $p<0.05$; ${ }^{*}$ denotes statistically significant difference after Benjamini-Hochberg adjustment.

\section{Discussion}

In our study we tested the hypothesis that $\beta$-AR polymorphisms influence cardiovascular measures noninvasively recorded using ECG, volume-clamp plethysmography and impedance cardiography in a group of healthy young subjects monitored at rest, during HUT representing orthostatic stress and while performing MA as a cognitive load. We selected parameters potentially influenced by sympathetic nervous system activity changes and our study protocol was developed to evoke sympathetic stimulation by two different ways.

In the following text, we report the results of previous studies describing functional effects of given polymorphism in $\beta$-AR in healthy subjects and compare them with our observations.

In $\beta_{1}$-AR coding gene, polymorphism rs1801252, only few previous studies found its association with resting HR with varying results. While in one study (Ranade et al. 2002) an increased HR was associated with allele A, in another study (Kumar et al. 2014) the same effect was connected with allele G. Only few other findings related to the effect of rs1801252 on cardiovascular parameters can be found in literature allele $\mathrm{G}$ was associated with a change in SI from baseline to HUT (Wittwer et al. 2011). Our results did not confirm these rare previous observations and indicate that the effect of this polymorphism is not significant considering both HR, BP and contractility related measures.

Polymorphism rs1801253 was up to now associated with increased HR in individuals carrying the allele C (Bruck et al. 2005) and a decreased risk of hypertension in carriers of allele G (Johnson et al. 2011). Previous studies focused on the influence on average BP yield only conflicting results (e.g. Gjesing et al. 2007, Tikhonoff et al. 2008).

In our study we did not confirm SNP related differences in HR or in BP, but we found consistently 
decreased $\mathrm{CO}$ and $\mathrm{CI}$ during all phases of our protocol in the carriers of allele G. CO is the amount of blood the heart pumps in $1 \mathrm{~min}$, and is dependent on the HR, contractility, preload and afterload. Increased contractility of the heart muscle, resulting in increased $\mathrm{CO}$ and the other hand impaired contractility, will reduce $\mathrm{CO}$ (Vincent 2008). Our observation can suggests, that decreased $\mathrm{CO}$ and even more importantly decreased $\mathrm{CI}$ could be related to decreased pumping activity of the heart in the carriers of allele G. Other two parameters, FTc and ETI were also decreased in the presence of allele $\mathrm{G}$ at rest and during mental stress. Both FTc and ETI are measures of normalized LVET - a decrease in them supports an assumption of a decreased cardiac pumping activity in the carriers of allele G. Our observations are in concert with previous studies demonstrating more enhanced inotropic effect of allele $\mathrm{C}$ during dobutamine stress echocardio-graphy (e.g. La Rosé et al. 2004, Kindermann et al. 2011). We confirmed these results only indirectly showing a negative effect of $\mathrm{G}$ allele on contractility.

Polymorphism rs1042713 of $\beta_{2}$-AR was in previous studies associated with BP changes. Carriers of allele G had increased BP values (Masuo et al. 2005, Snyder et al. 2006) and several studies demonstrated also increased risk of hypertension in this subgroup (Pereira et al. 2003, Ge et al. 2005). Our results did not confirm alterations in average BP values, but we observed an increased BPV associated with $G$ allele in this polymorphism. In more details, overall BPV (SD SBP, SD DBP) and LF power of BP oscillations (LF SBP, HF SBP) were increased at rest and during HUT in the carriers of allele G. In contrast to our results, no significant association between BPV and rs1042713 polymorphism was demonstrated in previous study recruiting subjects with a wider age range 18-30 years (Atala et al. 2015). To the best of our knowledge, our study is the first to demonstrate significant associations of polymorphism rs1042713 with increased BPV. The $\beta_{2}$-ARs could contribute to short-term regulation of BP by mediating cardiac chronotropy and peripheral vasodilation. Several studies have reported that increased BPV is associated with an increased risk of cardiovascular disease (Stergiou et al. 2014). One of the possible explanation of the increased BPV could be a decreased ability of the baroreflex to buffer BP perturbations (Elstad et al. 2001, Wray et al. 2001). Consequently, impaired BP control can contribute to the development of hypertension in future. However, this hypothesis requires further study.

Several previous studies regarding the effect of rs1042713 polymorphism demonstrated differences in HR or HRV (e.g. Matsunaga et al. 2007b, Yang et al. 2011) and in hemodynamic parameters (CO, SV, systemic vascular resistance, ejection fraction) (Tang et al. 2003, Wittwer et al. 2011). However, we did not find any significant association of hemodynamic or HR derived measures in our group of healthy young subjects during any phase of study protocol.

The effect of the polymorphisms rs1042714 was studied in several previous studies, but only in a few of them authors found significant associations. Several studies associated this SNP with alterations in average $\mathrm{BP}$, but their results are conflicting (Masuo et al. 2005, Binder et al. 2006). However, two studies agreed on the results, that allele $G$ is associated with an increase in HRV in LF band (Matsunaga et al. 2007a, Atala et al. 2015). Our results did not confirm these associations. On the other hand, we found decreased SI, together with decreased cardiac contractility related indices derived from impedance cardiography - VI and ACI - and increased PEP at rest and during MA phase in the allele $\mathrm{C}$ carriers compared to GG homozygotes. It is interesting, that SI, VI and ACI were constantly decreased during whole study protocol except for HUT, where the SNP related differences related disappeared. Our results suggest a possible effect of the presence of allele $\mathrm{C}$ in rs1042714 SNP on decreased cardiac contraction force. To compare our results with previous studies, no significant association of this SNP with SI at rest and during HUT was found (Wittwer et al. 2011), so the conclusions are still ambiguous. One of the possible explanations of this difference include a different methodology for SV and SI estimation (pulse contour method from blood pressure curve in previous study vs. impedance cardiography in our study) and much wider age range in above mentioned study (18-40 years).

Cardiovascular system control can be evaluated by diverse methods. In the studies aimed to find associations with SNPs, HR and HRV were analyzed most often. In other studies, BP or (not often) BPV was employed. However, to more comprehensively analyze changed sympathetic control including its chronotropic and inotropic components we assume that a simultaneous recording of various cardiovascular measures using diverse methodological approaches should be preferred. Having in mind that specific SNPs influenced different aspects of sympathetic cardiovascular control while 
leaving others without a significant change, our results underline the appropriateness of this approach. Most previous studies in this field evaluated cardiovascular parameters only at rest. Our results suggest that the subtle effects of genetic variations can be demasked by application of standardized stressor(s). We provide a new aspect into understanding of the $\beta$-AR SNPs effects taking into considerations a complexity of sympathetic cardiovascular control. Taken together, the effects of SNPs with in vitro demonstrated functional consequences on AR function are not always obvious on the level of whole human organism. These - when analyzed separately often subtle - effects can mutually interact or interfere with other risk factors finally resulting in the clinically important consequences including development of pathological states.

Autonomic nervous control assessment by evaluation of various cardiovascular and hemodynamic measures provides an important information on cardiac and vascular control state. Changes in these parameters in relation to various genotypes could indicate the potentially clinically important influence of the given genotype on autonomic nervous system function. A recognition of significant relations between gene polymorphism and resulting phenotype represents a progress in the better understanding of various disorders pathogenesis. In future, genotyping of individuals can contribute to the improved cardiovascular risk estimation with the perspective of earlier and more effective therapeutic intervention. It could represent an important step forward in the personalized medicine.

Several limitations to the interpretation of our findings should be considered. First, the sample size of our study was relatively small given the complexity of methodology, but it was higher than in the majority of previous studies on this topic. Because of small number of minor alleles in our sample size, we did not compare effects of two alleles presence: rs1801252: (AA+AG) vs. GG and rs1801253: (CC+CG) vs. GG. Second limitation is that we did not determine plasma norepinephrine and epinephrine levels, often used as indices of overall sympathetic activity. Thirdly, two pairs of SNPs are relatively closely located on the given gene. Since it is expected that these pairs are in linkage disequilibrium, the analysis of haplotypes effects was performed in several previous studies substituting separate analysis of given SNP. We plan to focus on haplotypes effects in the following study with an increased number of subjects to increase statistical power. Lastly, to decrease the risk of statistical error of type I (false rejection of true null hypothesis), we have employed Benjamini-Hochberg correction strategy after clustering of assessed parameters to subgroups. This liberal approach enables to decrease the risk of type I statistical error while preserving the statistical power. We should be aware of the false null hypothesis rejection but in the same time we tried to minimize the risk of statistical error of type II - failure to reject a null hypothesis that is false.

We conclude that complex analysis of various cardiovascular characteristics during various physiological states can reveal subtle differences in cardiovascular sympathetic control associated with $\beta$-ARs polymorphisms. SNPs of $\beta_{1}$-AR rs 1801253 and of $\beta_{2}$-AR rs1042714 are associated with altered contractility measures suggesting possible effect on the cardiac inotropy. SNP of $\beta_{2}$-AR rs 1042713 is associated with altered blood pressure variability indicating its effect on blood pressure control. Some of these effects were demonstrated only during rest or standardized stress conditions.

\section{Conflict of Interest}

There is no conflict of interest.

\section{Acknowledgements}

The study was supported by grants VEGA 1/0199/19, 1/0200/19, 1/0283/21 and Grant UK/175/2020.

\section{References}

AHLES A, ENGELHARDT S: Polymorphic variants of adrenoceptors: pharmacology, physiology, and role in disease. Pharmacol Rev 66: 598-637, 2014. https://doi.org/10.1124/pr.113.008219

AHLES A, ROCHAIS F, FRAMBACH T, BÜNEMANN M, ENGELHARDT S: A polymorphism-specific "memory" mechanism in the $\beta$ 2-adrenergic receptor. Sci Signal 4: ra53, 2011. https://doi.org/10.1126/scisignal.2001681

ARADILLAS-GARCÍA C, CRUZ M, PÉREZ-LUQUE E, GARAY-SEVILLA ME, MALACARA JM, ADUNA R, PERALTA J, BURGUETE-GARCÍA A, ALEGRÍA-TORRES JA: Obesity is associated with the Arg389Gly ADRB1 but not with the Trp64Arg ADRB3 polymorphism in children from San Luis Potosí and León, México. J Biomed Res 31: 40-46, 2017. https://doi.org/10.7555/JBR.30.20150169 
ATALA MM, GOULART A, GUERRA GM, MOSTARDA C, RODRIGUES B, MELLO PR, CASARINE DE, IRIGOYEN M-C, PEREIRA AC, CONSOLIM-COLOMBO FM: Arg16Gly and Gln27Glu $\beta 2$ adrenergic polymorphisms influence cardiac autonomic modulation and baroreflex sensitivity in healthy young Brazilians. Am J Transl Res 7: 153-161, 2015.

BENJAMINI Y, HOCHBERG Y: Controlling the false discovery rate: A practical and powerful approach to multiple testing. J R Statist Soc B 57: 289-300, 1995. https://doi.org/10.1111/j.2517-6161.1995.tb02031.X

BINDER A, GARCIA E, WALLACE C, KAZEEM G, BEN-SHLOMO Y, YARNELL J, BROWN P, CAULFIELD M, SKRABAL F, KOTANKO P, MUNROE P: Haplotypes of the beta-2 adrenergic receptor associate with high diastolic blood pressure in the Caerphilly prospective study. J Hypertens 24: 471-477, 2006. https://doi.org/10.1097/01.hjh.0000209983.28735.33

BONDAR G, TOGASHI R, CADEIRAS M, SCHAENMAN J, CHENG RK, MASUKAWA L, HAI J, BAO TM, CHU D, CHANG E, BAKIR M, KUPIEC-WEGLINSKI S, GROYSBERG V, GROGAN T, MELTZER J, KWON M, ROSSETTI M, ELASHOFF D, REED E, PING PP, DENG MC: Association between preoperative peripheral blood mononuclear cell gene expression profiles, early postoperative organ function recovery potential and long-term survival in advanced heart failure patients undergoing mechanical circulatory support. PLoS One 12: e0189420, 2017. https://doi.org/10.1371/journal.pone.0189420

BRODDE OE, MICHEL MC: Adrenergic and muscarinic receptors in the human heart. Pharmacol Rev 51: 651-690, 1999.

BRUCK H, LEINEWEBER K, TEMME T, WEBER M, HEUSCH G, PHILIPP T, BRODDE OE: The Arg389Gly Beta1adrenoceptor polymorphism and catecholamine effects on plasma-renin activity. J Am Coll Cardiol 46: 2111-2115, 2005. https://doi.org/10.1016/j.jacc.2005.08.041

BYLUND DB, EIKENBERG DC, HIEBLE JP, LANGER SZ, LEFKOWITZ RJ, MINNEMAN KP, MOLINOFF PB, RUFFOLO RR, TRENDELENBURG U: International Union of Pharmacology nomenclature of adrenoceptors. Pharmacol Rev 46: 121-136, 1994.

CHONG LK, CHOWDRY J, GHAHRAMANI P, PEACHELL PT: Influence of genetic polymorphisms in the $\beta 2$-adrenoceptor on desensitization in human lung mast cells. Pharmacogenetics 10: 153-162, 2000. https://doi.org/10.1097/00008571-200003000-00007

EISENACH JH, MCGUIRE AM, SCHWINGLER RM, TURNER ST, JOYNER MJ: The Arg16/Gly/ $\beta 2$-adrenergic receptor polymorphism is associated with altered cardiovascular responses to isometric exercise. Physiol Genomics 16: 323-328, 2012. https://doi.org/10.1152/physiolgenomics.00152.2003

ELSTAD M, TOSKA K, CHON KH, RAEDER EA, COHEN RJ: Respiratory sinus arrhythmia: Opposite effects on systolic and mean arterial pressure in supine humans. J Physiol 536: 251-259, 2001. https://doi.org/10.1111/j.1469-7793.2001.t01-1-00251.x

GE D, HUANG J, HE J, LI B, DUAN X, CHEN R, GU D: $\beta 2$-adrenergic receptor gene variations associated with stage-2 hypertension in northern Han Chinese. Ann Hum Genet 69: 36-44, 2005. https://doi.org/10.1046/j.1529-8817.2003.00093.x

GJESING AP, ANDERSEN G, ALBRECHTSEN A, GLÜMER C, BORCH-JOHNSEN K, JØRGENSEN T, HANSEN T, PEDERSEN O: Studies of associations between the Arg389Gly polymorphism of the $\beta 1$-adrenergic receptor gene (ADRB1) and hypertension and obesity in 7677 Danish white subjects. Diabet Med 24: 392-397, 2007. https://doi.org/10.1111/j.1464-5491.2006.02031.x

JAVORKA M, KROHOVA J, CZIPPELOVA B, TURIANIKOVA Z, LAZAROVA Z, WISZT R, FAES L: Towards understanding the complexity of cardiovascular oscillations: Insights from information theory. Comput Biol Med 98: 48-57, 2018. https://doi.org/10.1016/j.compbiomed.2018.05.007

JOHNSON AD, NEWTON-CHEH C, CHASMAN DI, EHRET GB, JOHNSON T, ROSE L, RICE K, VERWOERT GC, LAUNER LJ, GUDNASON V, LARSON MG, CHAKRAVARTI A, PSATY BM, CAULFIELD M, VAN DUIJN CM, RIDKER PM, MUNROE PB, LEVY D: Association of hypertension drug target genes with blood pressure and hypertension in 86588 individuals. Hypertension 57: 903-910, 2011. https://doi.org/10.1161/HYPERTENSIONAHA.110.158667 
JOHNSON JA, ZINEH I, PUCKETT BJ, MCGORRAY SP, YARANDI HN, PAULY DF: $\beta 1$-adrenergic receptor polymorphisms and antihypertensive response to metoprolol. Clin Pharmacol Ther 74: 44-52, 2003. https://doi.org/10.1016/S0009-9236(03)00068-7

KINDERMANN M, SEELAND U, RUHNKE P, BÖHM M, MAACK C: Functional effects of $\beta 1$-adrenoceptor polymorphisms on the hemodynamic response to dobutamine with and without b-blocker administration. Clin Res Cardiol 100: 129-137, 2011. https://doi.org/10.1007/s00392-010-0221-Z

KROHOVA J, CZIPPELOVA B, TURIANIKOVA Z, LAZAROVA Z, WISZT R, JAVORKA M, FAES L: Information domain analysis of respiratory sinus arrhythmia mechanisms. Physiol Res 67 (Suppl 4): S611-S618, 2018. https://doi.org/10.33549/physiolres.934049

KUMAR S, MISHRA A, SRIVASTAVA A, MITTAL T, GARG N, MITTAL B: Significant role of ADRB3 rs4994 towards the development of coronary artery disease. Coron Artery Dis 25: 29-34, 2014. https://doi.org/10.1097/MCA.0000000000000056

LA ROSÉE K, HUNTGEBURTH M, ROSENKRANZ S, BÖHM M, SCHNABEL P: The Arg389Gly beta1-adrenoceptor gene polymorphism determines contractile response to catecholamines. Pharmacogenetics 14: 711-716, 2004. https://doi.org/10.1097/00008571-200411000-00001

LEINEWEBER K, BRODDE OE: $\beta 2$-adrenoceptor polymorphisms: Relation between in vitro and in vivo phenotypes. Life Sci 74: 2803-2814, 2004. https://doi.org/10.1016/j.1fs.2003.10.025

LEVIN MC, MARULLO S, MUNTANER O, ANDERSSON B, MAGNUSSON Y: The myocardium-protective Gly-49 variant of the $\beta 1$-adrenergic receptor exhibits constitutive activity and increased desensitization and down-regulation. J Biol Chem 277: 30429-30435, 2002. https://doi.org/10.1074/jbc.M200681200

LI Y, YUAN H, SUN L, ZHOU Q, YANG F, YANG Z, LIU D: $\beta 2$-adrenergic receptor gene polymorphisms are associated with cardiovascular events but not all-cause mortality in coronary artery disease patients: A meta-analysis of prospective studies. Genet Test Mol Biomarkers 23: 124-137, 2019. https://doi.org/10.1089/gtmb.2018.0153

LU Y, WANG Y, ZOU L, LIANG X, ONG CN, TAVINTHARAN S, YUAN JM, KOH WP, PAN A: Serum lipids in association with type 2 diabetes risk and prevalence in a Chinese population. J Clin Endocrinol Metab 103: 671-680, 2018. https://doi.org/10.1210/jc.2017-02176

MAISANO DELSER P, RAVNIK-GLAVAČ M, GASPARINI P, GLAVAČ D, MEZZAVILLA M: Genetic landscape of Slovenians: Past admixture and natural selection pattern. Front Genet 9: 1-8, 2018. https://doi.org/10.3389/fgene.2018.00551

MASUO K, KATSUYA T, FU Y, RAKUGI H, OGIHARA T, TUCK ML: Beta2- and beta3-adrenergic receptor polymorphisms are related to the onset of weight gain and blood pressure elevation over 5 years. Circulation 111: 3429-3434, 2005. https://doi.org/10.1161/CIRCULATIONAHA.104.519652

MATSUNAGA T, YASUDA K, ADACHI T, GU N, YAMAMURA T, MORITANI T, TSUJIMOTO G, TSUDA K: Association of $\beta$-adrenoceptor polymorphisms with cardiac autonomic modulation in Japanese males. Am Heart J 154: 759-766, 2007. https://doi.org/10.1016/j.ahj.2007.03.053

MITRA SR, TAN PY, AMINI F: Association of ADRB2 rs1042713 with obesity and obesity-related phenotypes and its interaction with dietary fat in modulating glycaemic indices in Malaysian adults. J Nutr Metab 2019: 8718795, 2019. https://doi.org/10.1155/2019/8718795

PEREIRA AC, FLORIANO MS, MOTA GFA, CUNHA RS, HERKENHOFF FL, MILL JG, KRIEGER JE: $\beta 2$ adrenoceptor functional gene variants, obesity, and blood pressure level interactions in the general population. Hypertension 42: 685-692, 2003. https://doi.org/10.1161/01.HYP.0000085648.65419.17

RANADE K, JORGENSON E, H-H SHEU W, PEI D, AGNES HSIUNG C, CHIANG F, CHEN YI, PRATT R, OLSHEN RA, CURB D, COX DR, BOTSTEIN D, RISCH N: A polymorphism in the betal adrenergic receptor is associated with resting heart rate. Am J Hum Genet 70: 935-942, 2002. https://doi.org/10.1086/339621

SNIEDER H, DONG Y, BARBEAU P, HARSHFIELD GA, DALAGEOGOU C, ZHU H, CARTER ND, TREIBER FA: $\beta 2$-adrenergic receptor gene and resting hemodynamics in European and African American youth. Am J Hypertens 15: 973-979, 2002. https://doi.org/10.1016/S0895-7061(02)02991-6 
SNYDER EM, BECK KC, DIETZ NM, EISENACH JH, JOYNER MJ, TURNER ST, JOHNSON BD: Arg16Gly polymorphism of the $\beta 2$-adrenergic receptor is associated with differences in cardiovascular function at rest and during exercise in humans. J Physiol 571: 121-130, 2006. https://doi.org/10.1113/jphysiol.2005.098558

STAALSØ JM, ROKAMP KZ, OLESEN ND, LONN L, SECHER NH, OLSEN NV, MANTONI T, HELGSTRAND U, NIELSEN HB: ADRB2 gly16gly genotype, cardiac output, and cerebral oxygenation in patients undergoing anesthesia for abdominal aortic aneurysm surgery. Anesth Analg 123: 1408-1415, 2016. https://doi.org/10.1213/ANE.0000000000001563

STERGIOU GS, NTINERI A, KOLLIAS A, OHKUBO T, IMAI Y, PARATI G: Blood pressure variability assessed by home measurements: A systematic review. Hypertens Res 37: 565-572, 2014. https://doi.org/10.1038/hr.2014.2

TANG W, DEVEREUX RB, KITZMAN DW, PROVINCE MA, LEPPERT M, OBERMAN A, HOPKINS PN, ARNETT DK: The Arg16Gly polymorphism of the $\beta 2$-adrenergic receptor and left ventricular systolic function. Am J Hypertens 16: 945-951, 2003. https://doi.org/10.1016/S0895-7061(03)01001-X

TIKHONOFF $\mathrm{V}$, HASENKAMP S, KUZNETSOVA T, THIJS L, JIN Y, RICHART T, ZHANG H, BRAND-HERRMANN SM, BRAND E, CASIGLIA E, STAESSEN JA: Blood pressure and metabolic phenotypes in relation to the ADRB1 Arg389Gly and ADRA2B I/D polymorphisms in a white population. J Hum Hypertens 22: 864-867, 2008. https://doi.org/10.1038/jhh.2008.73

VINCENT JL: Understanding cardiac output. Crit Care 12: 12-14, 2008. https://doi.org/10.1186/cc6975

WITTWER ED, LIU Z, WARNER ND, SCHROEDER DR, NADEAU AM, ALLEN AR, MURILLO CJ, ELVEBAK RL, AAKRE BM, EISENACH JH: Beta-1 and beta-2 adrenergic receptor polymorphism and association with cardiovascular response to orthostatic screening. Auton Neurosci Basic Clin 164: 89-95, 2011. https://doi.org/10.1016/j.autneu.2011.07.004

WRAY DW, FORMES KJ, WEISS MS, O-YURVATI AH, RAVEN PB, ZHANG R, SHI X: Vagal cardiac function and arterial blood pressure stability. Am J Physiol Heart Circ Physiol 281: H1870-H1880, 2001. https://doi.org/10.1152/ajpheart.2001.281.5.H1870

YANG AC, TSAI S, HONG C, WANG C, CHEN T, LIOU Y, PENG C: Clustering heart rate dynamics is associated with $\beta$-adrenergic receptor polymorphisms: Analysis by information-based similarity index. PLoS One 6 : e19232, 2011. https://doi.org/10.1371/journal.pone.0019232

ZHANG F, STEINBERG SF: S49G and R389G polymorphisms of the $\beta 1$-adrenergic receptor influence signaling via the cAMP-PKA and ERK pathways. Physiol Genomics 45: 1186-1192, 2013. https://doi.org/10.1152/physiolgenomics.00087.2013 